David Jesson, School of Engineering (H6), University of Surrey,

Guildford, Surrey, UK, GU2 7XH

Tel: 00441483689627 Fax: 00441483686291 e-mail: d.jesson@ surrey.ac.uk

\title{
ORGANIC-INORGANIC HYBRID NANOPARTICLES: ADSORPTION CHARACTERISTICS OF POLYESTER RESINS
}

\section{D.A. Jesson ${ }^{1 *}$, M.-L. Abel ${ }^{1}$, A. Arkhireeva ${ }^{2}$, J.N. Hay ${ }^{2}$, P.A. Smith ${ }^{1}$ and J.F.Watts ${ }^{1}$}

${ }^{1}$ The Surface Analysis Laboratory, School of Engineering, University of Surrey, Guildford, Surrey, GU2 7XH

${ }^{2}$ Chemistry Division, SBMS, University of Surrey, Guildford, Surrey, GU2 7XH

\begin{abstract}
The adsorption of polyester onto organically modified silicas (ormosils) and (commercial) fumed silica has been compared utilising ToF-SIMS. The thermodynamics of each system was examined by constructing adsorption isotherm plots which indicated that the adsorption of polyester onto one of the modified silicas used may be a two stage process. Adsorption onto the fumed silica is in accord with the Langmuir model.
\end{abstract}




\section{KEYWORDS}

ToF-SIMS, silica, polyester, composites, adsorption

\section{INTRODUCTION}

In recent years, organic-inorganic hybrids have been developed as potential solutions to a wide array of problems including sensors ${ }^{1}$ and dye lasers ${ }^{2}$.

ORganically MOdified SILicaS (ormosils) are one type of organic-inorganic hybrid ${ }^{1}$. Work is currently underway to determine the efficacy of a range of ormosils (in nano-particulate form) as modifiers for polymers and polymer matrix composites. To understand the effect that the ormosils have on the matrix system it is important to appreciate the interaction between the ormosils and the matrix. This study presents an examination of the behaviour of two types of ormosil (ethyl and phenyl modified silicas), and a commercial fumed silica (of similar size to the nano-particulate ormosils). The aim of the study is to derive adsorption isotherms from ToF-SIMS data. Adsorption isotherms have been established as a reliable method for determining certain aspects of the chemistry between a substrate and an adsorbate, such as the strength of their interaction ${ }^{3-6}$. 


\section{EXPERIMENTAL}

\section{Materials}

Ethyl ( 60-70 nm diameter) and phenyl ( 100-160 nm) modified silica

nanoparticles were produced using a modified Stöber (hydrolytic) route ${ }^{7}$. HDK N20 (Wacker) is a commercial fumed silica used as a thixotropic agent in the production of a commercial polyester resin which is a matrix system under investigation. Samples of this resin, Crystic 2-406PA (Scott-Bader) were supplied without the fumed silica addition and this resin was used as the adsorbate. Figure 1 shows an example of the structure of the polyester resin, although this is included for illustrative purposes and cannot be assumed as to be completely characteristic. The model is based on statistical probability rather than a rigorous chemical analysis. Toluene (Fisher, T/2250/17, SpeciFied) was used to produce solutions of the resin, ranging between 0.1 and $10 \mathrm{vol} \%$, and to rinse off specimens at the end of the reaction time, thereby removing any poorly interacting or physically adsorbed molecules. Toluene was used following the technique of Fowkes ${ }^{8}$ whereby a solvent is found that is neutral with reference to both the adsorbent and the adsorbate. Another chemically suitable solvent would be for example $\mathrm{CCl}_{4}$, although this solvent poses difficulties from a Health and Safety standpoint. 
Thermodynamic Studies

Solutions of polyester in toluene were prepared in concentrations of $0.1,0.5,1,2.5$, $5,7.510$ vol\%. Samples of each of the three types of silicas massing $0.1 \pm 0.005 \mathrm{~g}$ were dispersed in solution for 30 minutes in an ultra-sonic bath, and were filtered using a Büchner filter funnel. The sample was filtered using excess toluene.

Analysis by ToF-SIMS

ToF-SIMS spectra over a range of 0-400 Da were produced using a VG Scientific type 23 system, utilising a Poschenrieder time-of-flight analyser with a liquid metal ion source. Static SIMS conditions were used (i.e. ion dose $<1 \times 10^{13}$ ions $\mathrm{cm}^{-2}$ ) with a pulsed primary ion beam $(50 \mathrm{~ns}$ at $5 \mathrm{kHz})$ of ${ }^{69} \mathrm{Ga}^{+}$at $16 \mathrm{kV}$.

\section{RESULTS AND DISCUSSION}

Adsorption of the polyester onto ethyl modified and phenyl modified silicas as well as a commercial fumed silica was studied. Figure 2a-c below compares the positive ion spectra of untreated samples of the three silicas. The spectra have been plotted using the relative peak intensity (RPI), which is calculated by 
$\mathrm{RPI}=\frac{\mathrm{I}_{\mathrm{p}}}{\mathrm{I}_{\mathrm{tot}}}$

where $I_{p}$ is the intensity of the peak of interest and $I_{\text {tot }}$ is the sum of the intensities of all the counts in the 5-200 Da region of the spectrum. It will be noted that, as might be expected, the spectrum of the commercial silica is comparatively very clean, with only 2 significant peaks at $28\left(\mathrm{Si}^{+}\right)$and $45\left(\mathrm{SiOH}^{+}\right)$and with little in the way of $\mathrm{C}_{\mathrm{x}} \mathrm{H}_{\mathrm{y}}$ fragment ions. The intensity of the 28 peak is much higher than in either of the two ormosils or in the case of the commercial silica upon which polyester has been adsorbed. The significant peak in the ethyl modified silica is the 29 peak $\left(\mathrm{C}_{2} \mathrm{H}_{5}{ }^{+}\right)$which in figure $1 \mathrm{~b}$ is almost as dominant as the 28 peak. By contrast, the 77 peak $\left(\mathrm{C}_{6} \mathrm{H}_{5}{ }^{+}\right)$is comparatively small in figure 1c, of the phenyl modified silica spectrum, (this is probably due to the difficulties associated with ionising larger fragments) but the disintegration of the phenyl component into smaller ring structures such as $39\left(\mathrm{C}_{3} \mathrm{H}_{3}{ }^{+}\right)$and $51\left(\mathrm{C}_{4} \mathrm{H}_{3}{ }^{+}\right)$also contributes to the spectrum. Significant peaks were isolated in the spectra from the adsorption experiments, and these were used to produce adsorption isotherms. Figures 3a-c show the polyester resin adsorption isotherm (trend lines have been added, although these have no mathematical significance and are simply a guide to the eye) associated with the 82 peak (from an as yet uncharacterised hydrocarbon fragment from the polyester), on all three silicas examined. Although the structure of $m / z=82 \mathrm{Da}$ has not yet been fully resolved (it is likely to be either $\mathrm{C}_{6} \mathrm{H}_{10}{ }^{+}$or 
$\mathrm{C}_{4} \mathrm{H}_{2} \mathrm{O}_{2}{ }^{+}$), it was chosen as a characteristic peak of the polyester which a) is not found in any of the silicas and b) is unusually intense. The test of whether or not adsorption data conform to the Langmuir model is to plot C/RPI vs. $\mathrm{C}$ (where $\mathrm{C}$ is the solute concentration), a linear relationship indicating that Langmuir conditions have been met. Linear regression has been carried out on the data produced from the three nano-particulate substrates, and the results are presented in Table 1. When these data are taken in conjunction with the adsorption isotherms, then in the case of the fumed silica and the phenyl ormosil, the data support the Langmuir model. The ethyl ormosil however seems to show multilayer adsorption. Watts et $\mathrm{al}^{3}$, faced, apparently with the problem of multilayer adsorption (since one of the key assumptions of the Langmuir model is that it applies only to monolayer adsorption), determined that they were in fact observing a conformational effect due to increasing numbers of polymer-solvent interactions in high concentration solutions, leading to perturbation of the polymer chains which in turn allows a higher packing density when adsorbed onto a substrate. The alternative would be that the polymer chains were interacting in the higher concentration solutions. The use of the approach of Kurata and Tsunashima ${ }^{9}$ showed that all the solutions used could be considered dilute and so the former argument was supported. This argument could be applied in the case of the ethyl modified silica, which would at first seem to show multilayer adsorption. Whilst it has not been possible to follow the approach of Kurata and Tsunashima in this case (due to insufficient information 
regarding the polyester) the molar concentrations are extremely small $(10 \mathrm{vol} \%=$ $\left.5.55 \times 10^{-3} \mathrm{M}\right)$. Therefore it is believed that the polyester is adsorbing onto the ethyl modified silica, but that at around $1 \mathrm{vol} \%\left(5.55 \times 10^{-4} \mathrm{M}\right)$ the configuration of adsorbed polyester chains changes slightly. This leads to an increase in the adsorbate on the substrate. In all three cases however it is believed that a chemisorption process is taking place and that this is possibly an acid-base interaction.

\section{CONCLUSIONS}

Adsorption of polyester onto ethyl and phenyl modified silica as well as onto a commercial fumed silica has been carried out. ToF-SIMS was utilised to produce spectra of the adsorbed surfaces, and characteristic peaksin the spectra were used to produce adsorption isotherms. The adsorption of the polyester onto the commercial silica and phenyl ormosil appear to produce Langmuir-type isotherms, whereas those produced from the ethyl ormosil were more complicated and suggest a two stage adsorption process. It is believed that this work, in parallel with mechanical testing of modified resin systems and composites, will lead to a successful method for the optimisation of specific ormosil types as modifiers for polymer matrices composite systems. 


\section{Acknowledgements}

The authors wish to thank the Engineering and Physical Sciences Research Council (EPSRC) and the Defence Science and Technology Laboratory (dstl) for their joint funding of this project, Scott-Bader for their support of this project and Andrew Brown for his assistance with the ToF-SIMS analyses.

\section{REFERENCES}

1. Bescher E, Mackenzie JD, Materials Science and Engineering C, 1998; 6: 145

2. Lebeau B, Sanchez C, Curr. Opinion Solid State Mater. Sci. 1999; 4: 11

3. Watts JF, Leadley SR, Castle JE, Blomfield CJ. Langmuir 2000; 16: 2292

4. Watts JF, Castle JE. Int. J. Adhes. Adhes. 1999; 19: 435

5. Houssiua L, Betrand P. Appl. Surf. Sci. 2003; 203-204; 580

6. Abel M-L, Chehimi MM, Brown AM, Leadley SR, Watts JF. J. Mater. Chem. 1995; 5: 845

7. Arkhireeva A, and Hay JN. J. Mater. Chem. 2003; 13, DOI: 10.1039 /b306994j

8. Fowkes FM, J. Adhes. Sci. Technol. 1987, 1, 7

9. Kurata M, and Tsunashima Y. In Polymer Handbook, $3^{\text {rd }}$; Brandrup J, Immergut EH (eds). John Wiley and Sons: New York, 1989 
Figure 1. Theoretical structure of the polyester. This structure is based on statistical probability of components present rather than a fully calculated series of chemical reactions.

Figure 2. ToF-SIMS spectra comparing untreated (a) commercial silica (b) ethyl modified silica and (c) phenyl modified silica

Figure 3a. Adsorption isotherm of polyester resin onto commercial silica

Figure $3 \mathrm{~b}$. Adsorption isotherm of polyester resin onto ethyl modified silica

Figure 3c. Adsorption isotherm of polyester resin onto phenyl modified silica

Table 1. $\mathrm{R}^{2}$ values for $\mathrm{C} / \mathrm{RPI}$ against $\mathrm{C}$ where $\mathrm{C}$ is the molar concentration of the solution plotted from the adsorption isotherms of peaks chosen from the ToF-SIMS spectra. The closer the $\mathrm{R}^{2}$ value is to 1 , the better the fit with the Langmuir type isotherm. As can be seen the commercial silica and the phenyl ormosil conform reasonably well to the Langmuir isotherm whereas the ethyl modified seems to show two sets of data. 


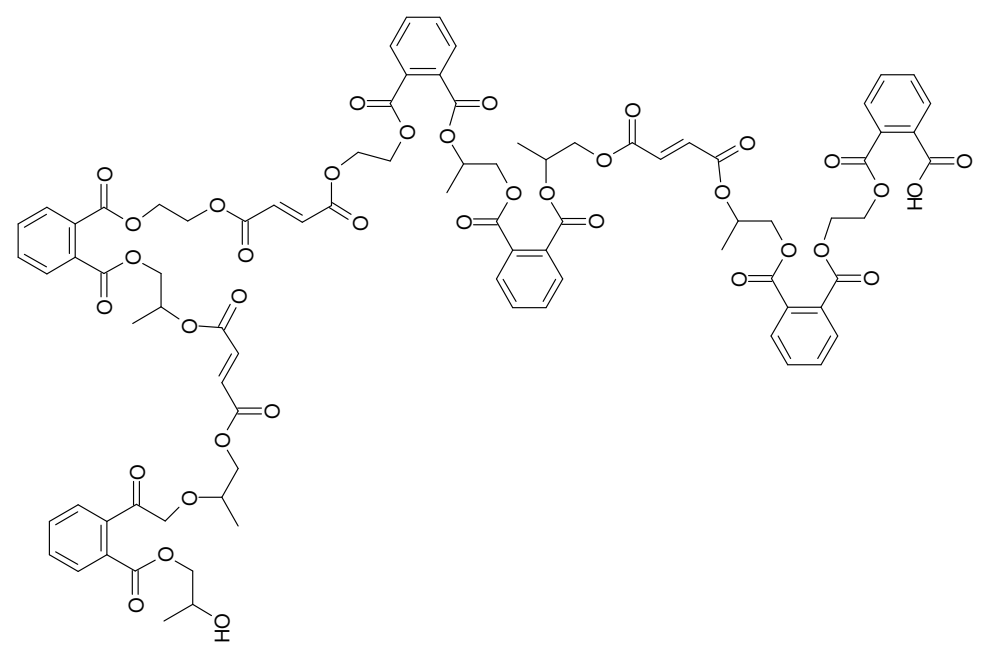

Figure 1. Theoretical structure of the polyester. This structure is based on statistical probability of components present rather than a fully calculated series of chemical reactions. 

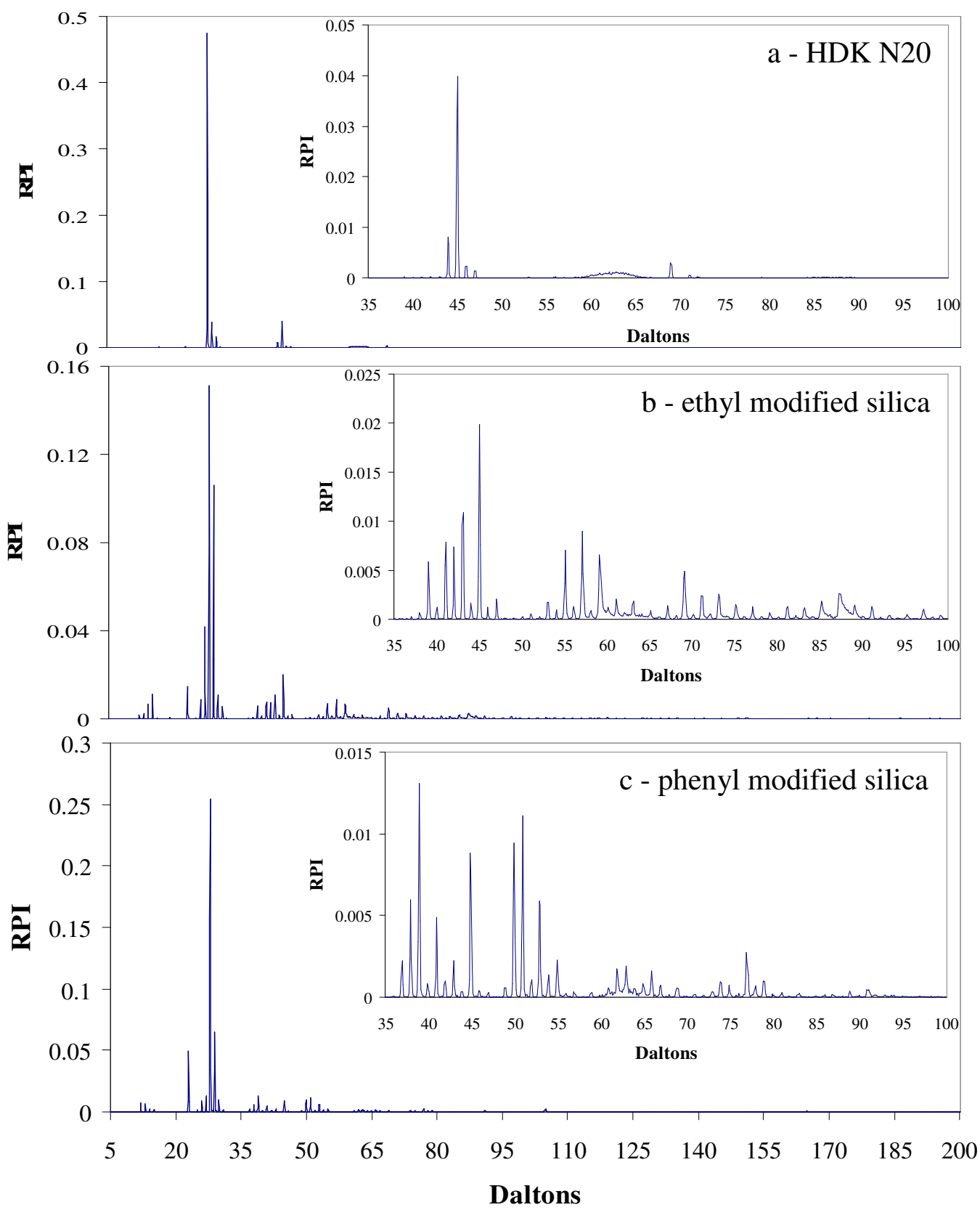

Figure 2. ToF-SIMS spectra comparing untreated (a) commercial silica (b) ethyl modified silica and (c) phenyl modified silica 
HDK N20 - 82 Peak

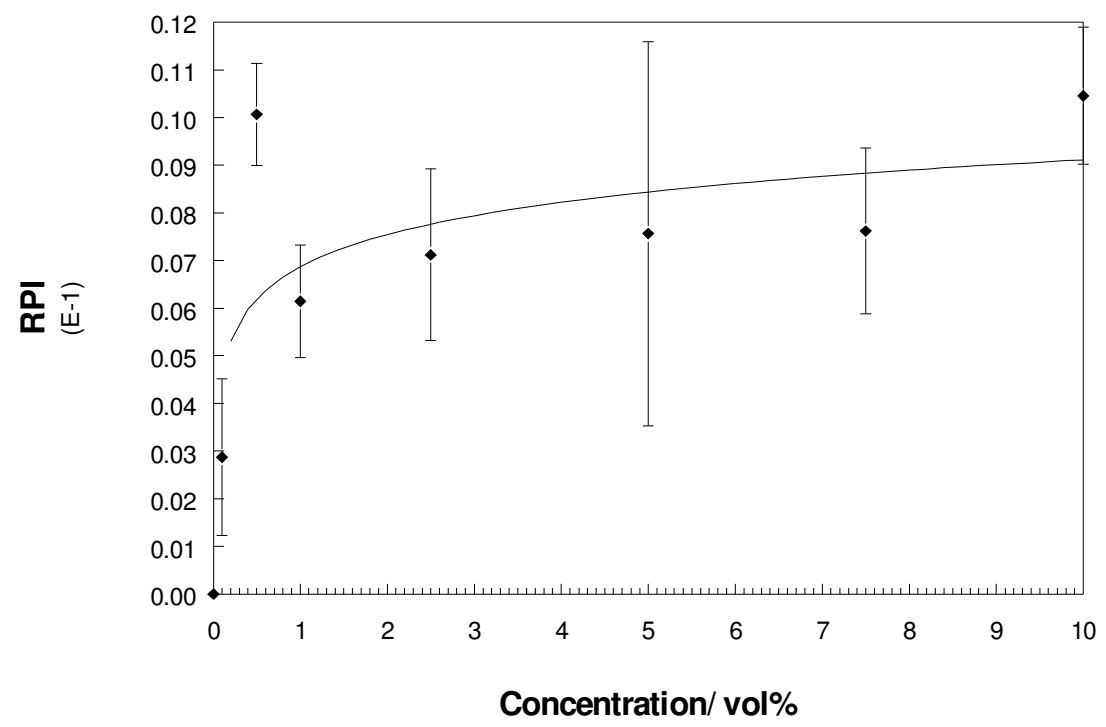

Figure 3a Adsorption isotherm of polyester resin onto commercial silica

Ethyl Modified - 82 peak

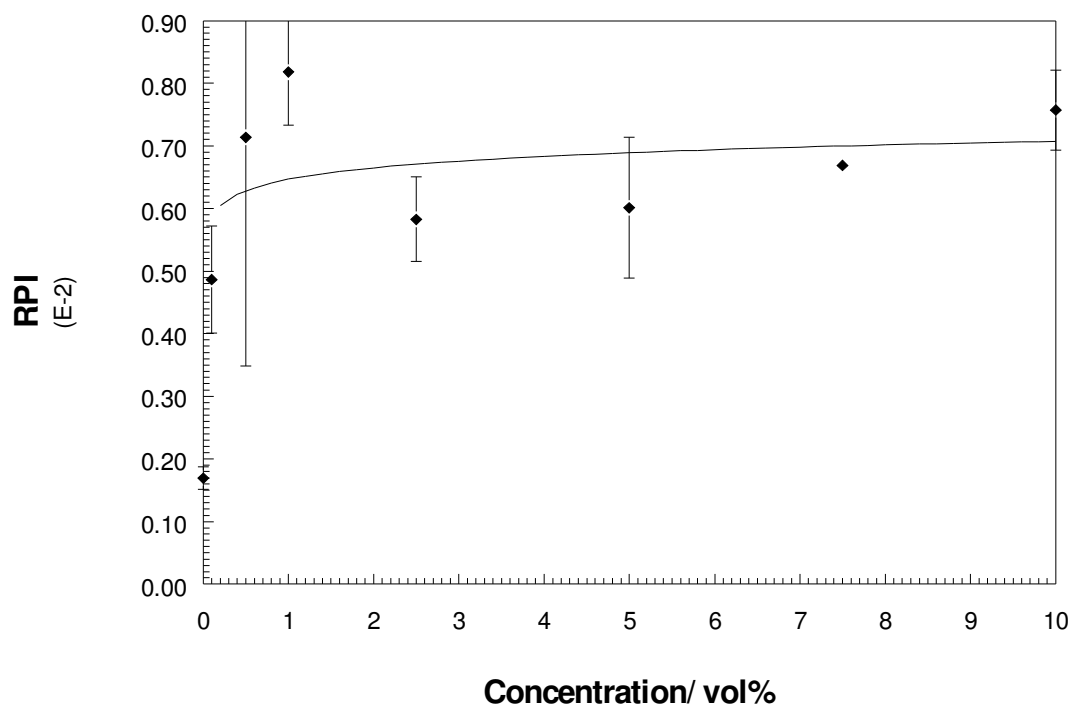

Figure $3 \mathrm{~b}$ Adsorption isotherm of polyester resin onto ethyl modified silica 
Phenyl modified - 82 peak

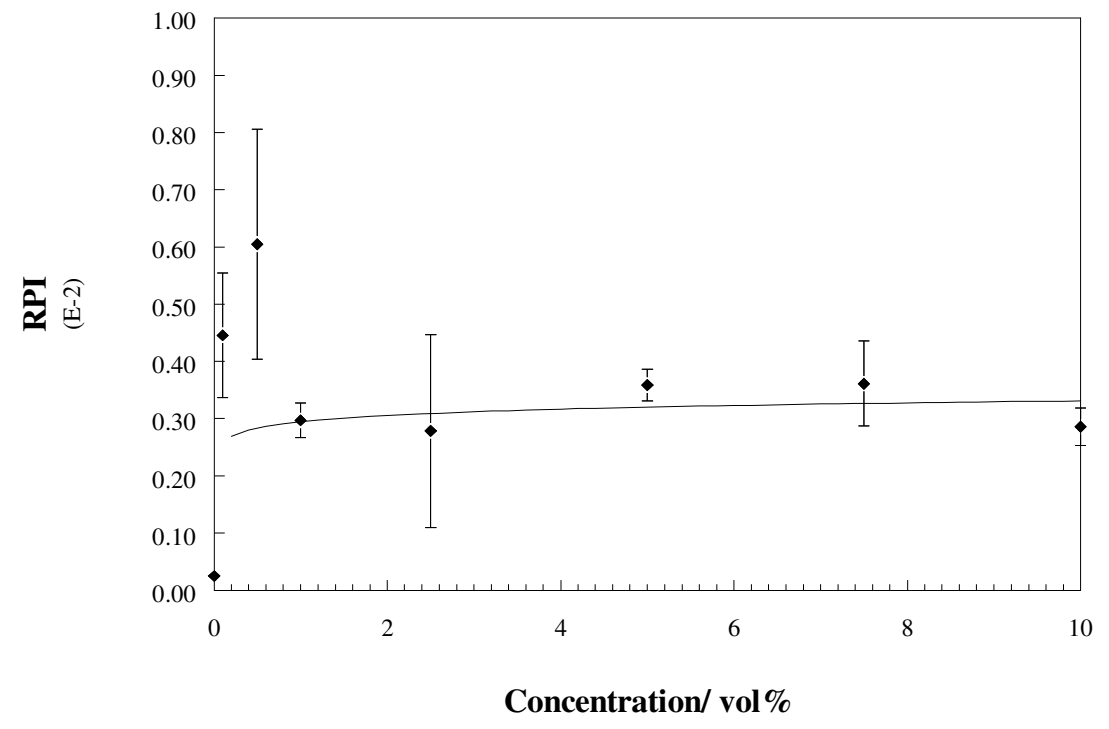

Figure 3c. Adsorption isotherm of polyester resin onto phenyl modified silica

\begin{tabular}{|c|c|c|c|c|c|c|c|}
\hline \multicolumn{2}{|c|}{ fumed silica } & \multicolumn{4}{|c|}{ ethyl modified } & \multicolumn{2}{|c|}{ phenyl modified } \\
\hline Peak & $\mathrm{R}^{2}$ & Peak & $\mathrm{R}^{2}$ & $\begin{array}{c}R^{2} \\
(0-2.5 \% \mathrm{sol})\end{array}$ & $\begin{array}{c}R^{2} \\
(2.5-10 \% \text { sol })\end{array}$ & peak & $\mathrm{R}^{2}$ \\
\hline 77 & 0.9713 & 77 & 0.3208 & 0.7779 & 0.9863 & 67 & 0.985 \\
\hline 82 & 0.9523 & 82 & 0.0745 & 0.9704 & 0.9889 & 82 & 0.9771 \\
\hline 87 & 0.9801 & 149 & 0.0288 & 0.8136 & 0.9999 & 104 & 0.9817 \\
\hline
\end{tabular}

Table 1 . $\mathrm{R}^{2}$ values for $\mathrm{C} / \mathrm{RPI}$ against $\mathrm{C}$ where $\mathrm{C}$ is the molar concentration of the solution plotted from the adsorption isotherms of peaks chosen from the ToF-SIMS spectra. The closer the $\mathrm{R}^{2}$ value is to 1 , the better the fit with the Langmuir type isotherm. As can be seen the commercial silica and the phenyl ormosil conform reasonably well to the Langmuir isotherm whereas the ethyl modified seems to show two sets of data. 
